\title{
PERFORMANCE ANALYSIS OF ACTIVE POWER FILTER CONTROLLERS FOR HARMONICS MITIGATION IN POWER SYSTEMS
}

\author{
BasamaAbd El-Rahman ${ }^{1}$, E. G. Shehata ${ }^{2}$, Abou-Hashima El-Sayed ${ }^{3}$, Y. S.Mohamad ${ }^{4}$ \\ ${ }^{1}$ Electrical Engineer, Beni-Suef University, Egypt engbasma44@yahoo.com \\ ${ }^{2}$ Electrical Engineering Dept., Faculty of Engineering, Minia University, Egypt emadgameil@ @u.edu.eg \\ ${ }^{3}$ Electrical Engineering Dept., Faculty of Engineering,Minia University, Egypt \\ dr_mostafa555@yahoo.com \\ ${ }^{4}$ Electrical Engineering Dept., Faculty of Engineering,Minia University, Egyptdr.yehia60@ yahoo.com
}

\begin{abstract}
Shunt Active Power Filter (APF) is one of most preferred filters for the mitigation of harmonics in power systems. The controller part of shunt APF plays an important role to generate a reference current which compensate/cancel the distorted currents. The APF injects current equal but opposite to the harmonic components, in turn the fundamental components only flows in the point of common coupling (PCC). In this studying, for four controls algorithm are proposed to control the shunt active filter. Instantaneous Active-Reactive Power Theory (PQ), an adaptive phase locked loop (PLL), Instantaneous active and reactive current method (DQ) and Synchronous detection method (SD) are designed to generate the reference current of APF for mitigation of harmonics. The performance of the four methods are analyzed and compared under different operating conditions. The load is assumed to have high nonlinear characteristics.

Digital simulations are carried out to demonstrate the performance of the proposed algorithms using matlab/Simulink software package.
\end{abstract}

Keywords : Active power filter; Harmonics; PQ theory; PLL method, DQ method; SD method.

\section{INTRODUCTION}

Recently, the improved power quality becomes a higher demand as a result of the fast advancement in industry and technology. However, most of the control systems in industry depends mainly on power electronic devices (converters and inverters).Variable speed drives, conveyers, air conditioning, fluorescent and led lamps are becoming now essential in the industrial applications. The nonlinear characteristics of these systems reduce the level of electric power quality [13]. Moreover, it becomes more and more difficult to supply the consumer with clean electric power.

Electric drives and power electronic devices are used to improve the control system performance and response. Also, the total cost and the efficiency improved as a results of replacing the mechanical variable speed system with electrical ones. However, the electric drives and power conditioning devices increase the distortion level on the current and voltage in the electric power grids. The power conditioning devices draw harmonic currents from the electric grid and in turn the harmonic voltage will then be generated. The harmonic voltages are generated because the harmonic current causes nonlinear voltage drop across the grid impedance. The nonlinear current or voltage has components at frequencies other than the fundamental one (harmonics), and also has negative and zero sequences components. These components are harmful to all the electrical equipment of the power supply utilities and those of the customers. - 77 - 
Harmonic distortion causes different problems in power grid and consumer products, such as equipment overheating, capacitor fuse blowing, transformer overheating, malfunction of control/protection devices, and excessive neutral current [4-7].

Moreover, it is well known that the induction motor have poor power factor because of high magnetizing current value. Low power factor means drawing more reactive current component from the grid and in turn the system losses will increase and the power network stability will be weak [8].

Harmonic filters are very much necessary for the harmonic compensation, improving the power quality and increase the reliability of the electric power system [9]. There are two types of harmonic filters, passive power filters (PPFs) and active Power filters (APFs).

PPFs are simple construction and low cost. PPFs are inserted in parallel at the point of common coupling. Design of PPFs includes determining the types, put number, elements, and parameters of filters to satisfy the requirements of harmonic filtering, power factor correction, and other conditions. The PPFs consist of resistive, inductive and capacitive component. The performance of PPFs is based not only on circuit structure but also by the values of these components. The types of PPFs are a single-tuned filter, secondorder damped filter, third-order damped filter, and C-type damped filter [10], and [11].

Although PPFs are simple and least costly, they have drawbacks of large size, resonance, fixed compensation performance and low transient response. Moreover, over or undercompensation of harmonics can occur with load variation or system parameter variation. To overcome these problems, active power filters (APFs) have been studied and developed [8]. Active power filter is a controlled passive power filter by inserting active element (controlled element such as transistors) beside the passive element.

In this paper, four control algorithms are proposed to regulate the switching of shunt active filters. An instantaneous Active and Reactive Power method (PQ), adaptive phase locked loop (PLL) method, Instantaneous active and reactive current method (DQ) and
Synchronous detection method (SD) are studied to generate the reference current of APF and mitigation of harmonics. The performance of the four methods are analyzed and compared under different operating conditions, i.e., nonlinear loads, unbalanced and/or harmonically grid voltage.

\section{ACTIVE POWER FIL TERS}

Active power filters are an up-to-date solution for power quality problems. Figure 1 shows the general configuration of the active power filters. APFs can be classified based on inverter type to current source and voltage source active filters. Voltage source active power filter is preferred type because of its high efficiency, light weight and low cost. Moreover, multilevel and multistep voltage source inverters are developed.

Based on the connection of active filters, they can be classified into four types as shunt, series, hybrid and universal APFs [12]. Shunt active power filter is the most common type of active filters. Shunt active filters can be a voltage source or current source. This type is connected in parallel with the nonlinear load and designed at the PPC rated voltage [13].

Series active power filters are inserted in series between source and nonlinear loads and compensates the harmonic current of the nonlinear load and the voltage source harmonics. It is designed at the load rated current.

Hybrid active power filters is a hybrid of active and passive filters. This configuration is designed to reduce the initial cost of the filter and improve the efficiency. In this configuration, the switching frequency of the active filter is decreased. This type of APFs provide a solution of the problem of high fundamental current through the series active filter and high fundamental voltage across the shunt active filter.

Universal active filters are a hybrid of series and shunt active filters. This type of filter are designed to reduce the voltage and current harmonics at the source and load in the same time. Shunt and series active power filters can be located at the source and load, respectively, or vice versa. 
The core of the active power filter is the control algorithm which generates the reference current. Different control algorithms such as active and reactive power (P-Q) theory, Instantaneous active and reactive current (D-Q) theory, Phase-locked loop (PLL) method, Adaptive control, NeuroFuzzy, sliding mode control, delta-sigma modulation, vector control and repetitive control, Synchronous detection (SD) Method [14-16]. However, most of methods suffer from complexity and a lot of measurement signals.

In the following sections, P-Q method, Adaptive PLL method, D-Q method and SD method are explained.

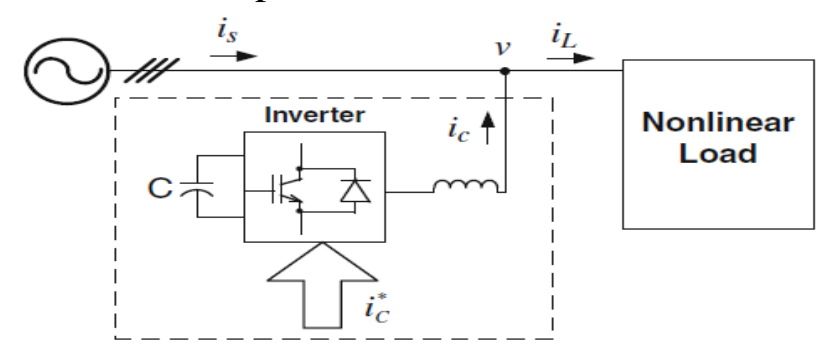

\section{APF controller design based on PQ theory}

In this method, the reference current is estimated based on the active and reactive power components. Then, the reference current is used to generate the switching state of the inverter. The P-Q theory is based on a transformation from a stationary reference system in $a-b-c$ coordinates, to a system $\alpha-\beta-0$ coordinates. The block diagram of the P-Q theory is shown in Fig. 2[17-19]. The threephase system voltages and load current in the $a-b-c$ coordinates are transformed to the $\alpha-\beta$ coordinates as follows:

Fig.1. Shunt Active power filter configuration.

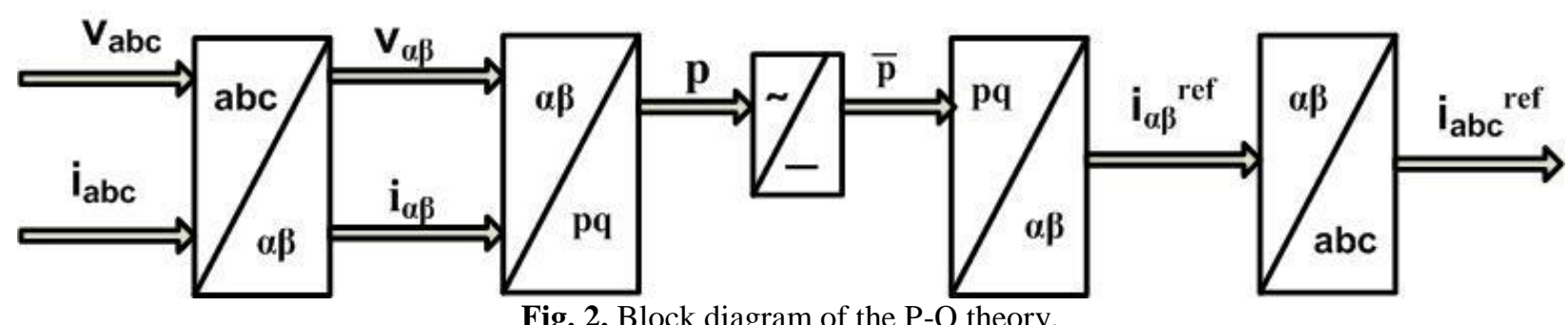

Fig. 2. Block diagram of the $\mathrm{P}-\mathrm{Q}$ theory.

$$
\begin{aligned}
& {\left[\begin{array}{l}
V_{\alpha} \\
V_{\beta}
\end{array}\right]=\sqrt{\frac{2}{3}}\left[\begin{array}{ccc}
1 & -\frac{1}{2} & -\frac{1}{2} \\
0 & \frac{\sqrt{3}}{2} & -\frac{\sqrt{3}}{2}
\end{array}\right]\left[\begin{array}{l}
V_{a} \\
V_{b} \\
V_{c}
\end{array}\right](1)} \\
& {\left[\begin{array}{l}
I_{\alpha} \\
I_{\beta}
\end{array}\right]=\sqrt{\frac{2}{3}}\left[\begin{array}{ccc}
1 & -\frac{1}{2} & -\frac{1}{2} \\
0 & \frac{\sqrt{3}}{2} & -\frac{\sqrt{3}}{2}
\end{array}\right]\left[\begin{array}{l}
i_{a} \\
i_{b} \\
i_{c}
\end{array}\right](2)}
\end{aligned}
$$

The instantaneous active and reactive power for the three-phase system is as follows:

$$
\left[\begin{array}{l}
P \\
Q
\end{array}\right]=\left[\begin{array}{cc}
V_{\alpha} & V_{\beta} \\
-V_{\beta} & V_{\alpha}
\end{array}\right]\left[\begin{array}{l}
I_{\alpha} \\
I_{\beta}
\end{array}\right]
$$

where $\mathrm{P}$ is the instantaneous real power and $\mathrm{Q}$ is the instantaneous reactive power.
By detecting the formulations of $\mathrm{P}$ and $\mathrm{Q}$, it is possible to put them in the following form:

$$
\begin{gathered}
P=\bar{P}+\check{P} \\
Q=\bar{Q}+\check{Q}
\end{gathered}
$$

where $\mathrm{P}$ is the DC component related to fundamental active current conventional. $\breve{P}$ is the AC component of $\mathrm{P}$, and related with harmonic caused by the $\mathrm{AC}$ component of instantaneous real power. $Q$ is the DC component related to the reactive power generated by the components fundamental currents and voltages. $\check{Q}$ is the AC component of $\mathrm{q}$ and related to harmonic currents caused by the AC components instantaneous reactive power. 
The reference currents $\mathrm{I}_{\text {ref }}$ are calculated as follows:

$$
\left[\begin{array}{l}
I_{\alpha}^{r e f} \\
I_{\beta}^{r e f}
\end{array}\right]=\frac{1}{V_{\alpha}^{2}+V_{\beta}^{2}}\left[\begin{array}{cc}
V_{\alpha} & -V_{\beta} \\
V_{\beta} & V_{\alpha}
\end{array}\right]\left[\begin{array}{l}
P \\
Q
\end{array}\right]
$$

Using equations (4) and (5), the reference current can be estimated as:

$\left[\begin{array}{l}I_{\alpha}^{r e f} \\ I_{\beta}^{r e f}\end{array}\right]=$

$\frac{1}{\Delta}\left[\begin{array}{cc}V_{\alpha} & -V_{\beta} \\ V_{\beta} & V_{\alpha}\end{array}\right]\left[\begin{array}{c}\bar{P} \\ Q\end{array}\right]+\frac{1}{\Delta}\left[\begin{array}{cc}V_{\alpha} & -V_{\beta} \\ V_{\beta} & V_{\alpha}\end{array}\right]\left[\begin{array}{l}\check{P} \\ \check{Q}\end{array}\right]$

where $\Delta=V_{\alpha}^{2}+V_{\beta}^{2}$

By using inverse transformation, the three phase reference currents are calculated as:

$$
\left[\begin{array}{ll}
I_{\text {ref }} 1 \\
I_{\text {ref }} 2 \\
I_{\text {ref }} & 3
\end{array}\right]=\sqrt{\frac{2}{3}}\left[\begin{array}{cc}
1 & 0 \\
-\frac{1}{2} & \frac{\sqrt{3}}{2} \\
-\frac{1}{2} & -\frac{\sqrt{3}}{2}
\end{array}\right]\left[\begin{array}{l}
I_{\alpha}^{r e f} \\
I_{\beta}^{r e f}
\end{array}\right]
$$

The analysis of this method assumes that the source voltage are ideal (pure sinusoidal and

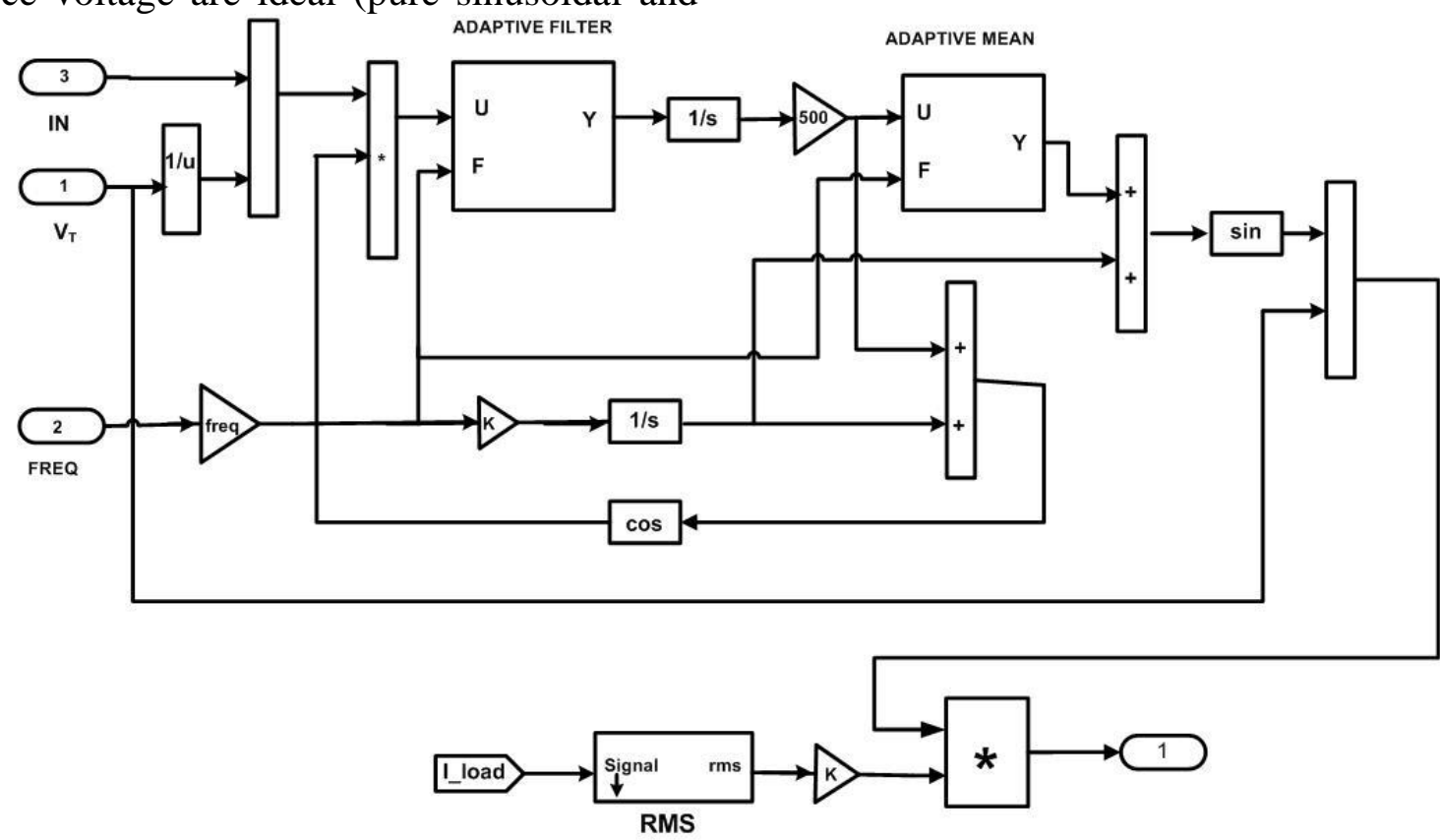

Fig. 3. Proposed reference signal generation (Adaptive PLL).

\section{APF controller design based on DQ method}

In this method, the reference current is estimated based on the instantaneous active and reactive current components id and iq of the nonlinear load. Then, the reference current balanced). Practically, source voltage may be unbalanced and/or distorted; and in turn, the control performance using the P-Q theory may be unsatisfactory under these conditions.

\section{APF controller design based on adaptive PLL method}

PLL systems are used in different industrial fields such as motor drives, induction heating and power supplies. Also, in the field of renewable energy integration, PLL systems have been used for synchronization process between grid-interfaced converters and the utility network even under unbalanced harmonic grid voltage[20-22].

When the network has high distorted current and unbalanced loads, Adaptive phase-locked loop is used to calculate the reference current. Adaptive PLL consists of three control units that individually control frequency, load current and voltage source. In control frequency unit, the fundamental frequency of the pure sinusoidal signal is extracted as shown in Fig. 3. [23]. 
coordinates. Two different transformation matrix need to be required Clarks Transformation and parks transformation, the transformations are defined by equations $9,10[24,25]$

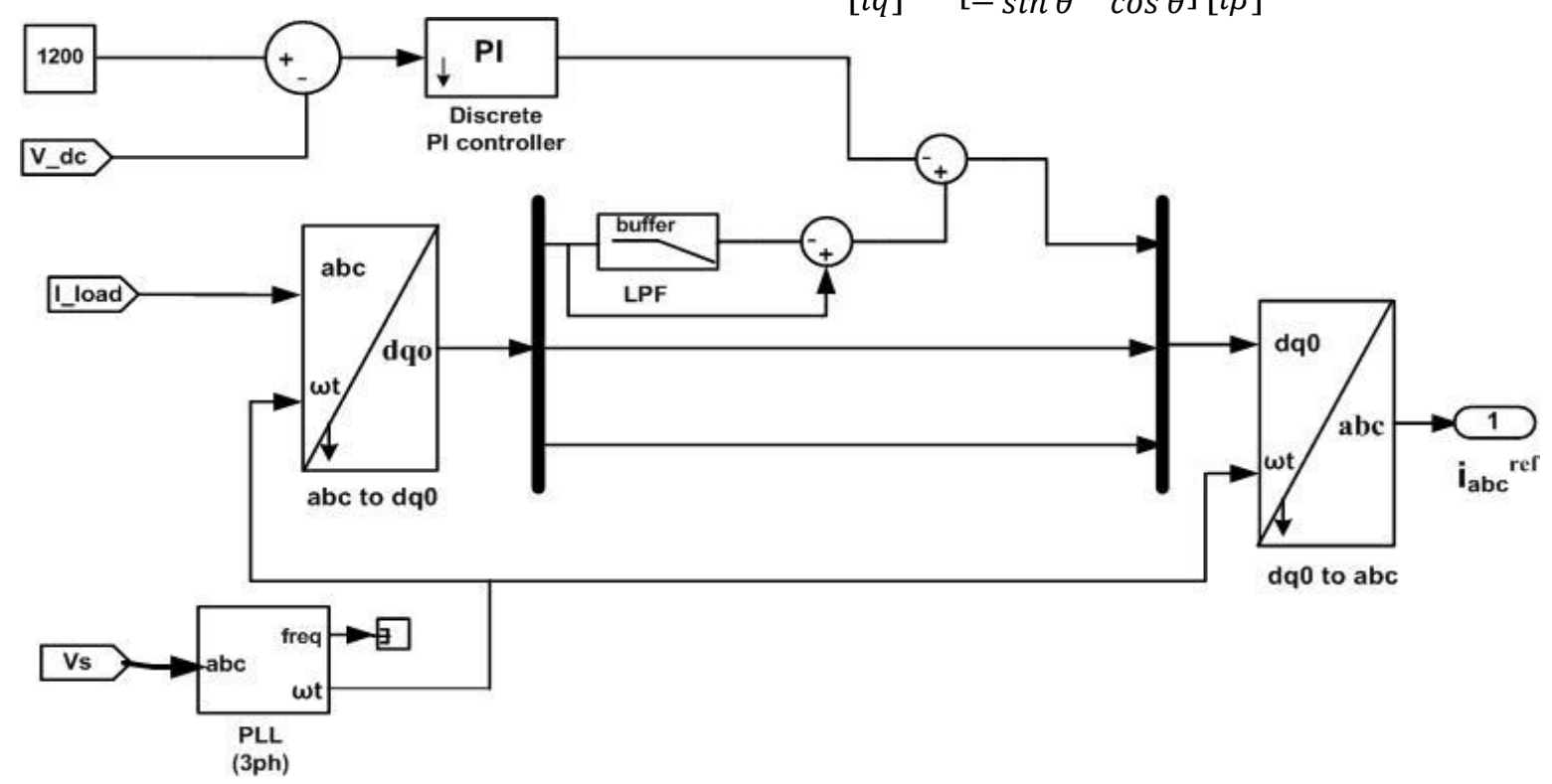

$\left[\begin{array}{c}i \alpha \\ i \beta \\ i 0\end{array}\right]=\sqrt{\frac{2}{3}}\left[\begin{array}{ccc}1 & -1 / 2 & -1 / 2 \\ 0 & \sqrt{3} / 2 & -\sqrt{3} / 2 \\ 1 / \sqrt{2} & 1 / \sqrt{2} & 1 / \sqrt{2}\end{array}\right]\left[\begin{array}{l}i a \\ i b \\ i c\end{array}\right]$

Fig.4. Block diagram of the D-Q theory.

A synchronous reference frame Phase Locked Loop (PLL) scheme is used to determine the frequency and phase angle of fundamental voltage for the $\mathrm{dq}$ reference frame ( $\theta$ ) [26].Rotating reference frame $d-q$ transformations are used for extracting fundamental and harmonic currents. The corresponding fundamental current is transformed to DC component while harmonic components are transformed to $\mathrm{AC}$ components in the frame. Therefore, the AC components can be filtered out by low pass filtering(LPF). After an inverse $d-q$ transformation in the respective frame, the unfiltered DC components are transformed back to corresponding harmonic. A targeted frequency component can then be separated from other frequency components in harmonic load currents. Now inverse transformation is performed to transform the currents from two - phase synchronous frame d-q into two-phase stationary frame $\alpha-\beta$ as per equation (11).

$$
\left[\begin{array}{l}
i \alpha \\
i \beta
\end{array}\right]=\left[\begin{array}{cc}
\cos \theta & -\sin \theta \\
\sin \theta & \cos \theta
\end{array}\right]\left[\begin{array}{c}
i d h \\
i q
\end{array}\right]
$$

Finally the current from two phase stationary frame $\alpha \beta 0$ is transformed back into threephase stationary frame $a-b-c$ as per equation
(12) and the compensation reference currents $\mathrm{ia}^{*}, \mathrm{ib}^{*}$ and ic* are obtained.

$$
\left[\begin{array}{l}
i a * \\
i b * \\
i c *
\end{array}\right]=\sqrt{\frac{2}{3}}\left[\begin{array}{ccc}
1 & 0 & 1 / \sqrt{2} \\
-1 / 2 & \sqrt{3} / 2 & 1 / \sqrt{2} \\
-1 / 2 & -\sqrt{3} / 2 & 1 / \sqrt{2}
\end{array}\right]\left[\begin{array}{l}
i \alpha \\
i \beta \\
i 0
\end{array}\right]
$$

One of the most important characteristics of this algorithm is that the reference currents are obtained directly from the loads currents without considering the source voltages. This is an important advantage since the generation of the reference signals is not affected by voltage unbalance or voltage distortion, therefore increasing the compensation robustness and performance[27]. The DQ is selected for the harmonic detection because this method provide the fast calculation time in which it is suitable for the real time application.

\section{APF controller design based on SD method}

The block diagram of the SD theory is shown in Fig.5. In this algorithm, the three-phase source currents are assumed to be balanced and the power factor will be unity after 
compensation [28]. So, the real power consumed by the load could be calculated from the instantaneous voltages and load currents. Under balancing source current condition (after compensation):

$\mathrm{Iam}=\mathrm{Ibm}=\mathrm{Icm}$

The active power per phase:

$\mathrm{Pa}=\frac{\mathrm{Vam} * \mathrm{Iam}}{2}$

where $\mathrm{Vm}$ and $\mathrm{Im}$ are the maximum voltage and current values, respectively.

The phase currents can be estimated as follows:

$\mathrm{Iam}=\frac{2 \mathrm{~Pa}}{\mathrm{Vam}}, \mathrm{Ibm}=\frac{2 \mathrm{~Pb}}{\mathrm{Vbm}}, \mathrm{Icm}=\frac{2 \mathrm{Pc}}{\mathrm{Vcm}}$

Using equations 14 and 15 , the relation

between phase powers can be deduced as:

$\mathrm{Pb}=\frac{\mathrm{Vbm}}{\mathrm{Vam}} * \mathrm{~Pa}, \quad \mathrm{Pc}=\frac{\mathrm{Vcm}}{\mathrm{Vam}} * \mathrm{~Pa}$

The total active power equals the sum of three phase powers:

$$
\begin{aligned}
& \mathrm{Pt}=\mathrm{Pa}+\mathrm{Pb}+\mathrm{Pc} \\
& \mathrm{Pt}=\mathrm{Pa}\left(\frac{\mathrm{Vt}}{\mathrm{Vam}}\right)
\end{aligned}
$$

$$
\text { whree, Vt }=\mathrm{Vam}+\mathrm{Vbm}+\mathrm{Vcm}
$$

The compensation currents are then calculated as:

$$
\begin{aligned}
& \operatorname{Isa}(t)=\frac{2 \mathrm{~Pa}}{\mathrm{Vam}}=\left(\frac{2 * \mathrm{Pt}}{\mathrm{Vam} * \mathrm{Vt}}\right) * \mathrm{Va}(\mathrm{t}) \\
& \operatorname{Isb}(\mathrm{t})=\frac{2 \mathrm{~Pb}}{\mathrm{Vbm}}=\left(\frac{2 * \mathrm{Pt}}{\mathrm{Vbm} * \mathrm{Vt}}\right) * \mathrm{Vb}(\mathrm{t}) \\
& \operatorname{Isc}(\mathrm{t})=\frac{2 \mathrm{Pc}}{\mathrm{Vcm}}=\left(\frac{2 * \mathrm{Pt}}{\mathrm{Vcm} * \mathrm{Vt}}\right) * \mathrm{Vc}(\mathrm{t})
\end{aligned}
$$

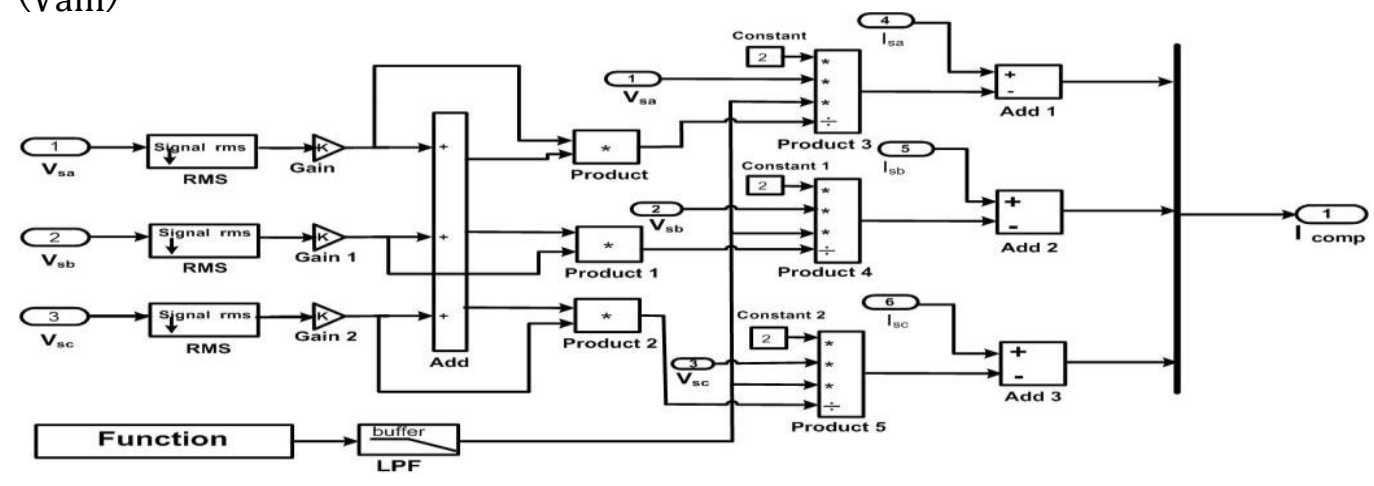

Function $=P_{3 \varnothing}=\left(V_{s a}{ }^{*} I_{s a}\right)+\left(V_{s b}{ }^{*} I_{s b}\right)+\left(V_{s c}{ }^{*} I_{s c}\right)$

Fig. 5. Block diagram of the SD theory.

It is not a necessary condition that the threephase voltage should be balanced. The advantage of this is that it leads to very much greater flexibility in wider application of reactive and harmonic current compensation in any operating distribution system where the feeder lines may lose voltage balance [28]. In addition, this method can be extensively used for compensation of reactive power, current imbalance and mitigation of current harmonics. It is the simplest method as it requires minimum calculations. However this method suffers a drawback from individual harmonic detection and its mitigation [29-30].

\section{Simulation results and discussions}

The system is simulated in MATLAB as shown in Fig. 6. The system parameters selected for the simulation studies are given in table 1. Time simulation is $0.1 \mathrm{sec}$. A shunt active power filter is applied at 0.05 second. The simulation cases are divided into three cases

of different supply conditions:

First case: the three-phase source voltages are assumed balanced and sinusoidal. The load is nonlinear. 
Second case: the three-phase source voltages are assumed distortion and the load is nonlinear.
Third case: the three-phase source voltages are assumed unbalance at magnitude and the load is nonlinear.

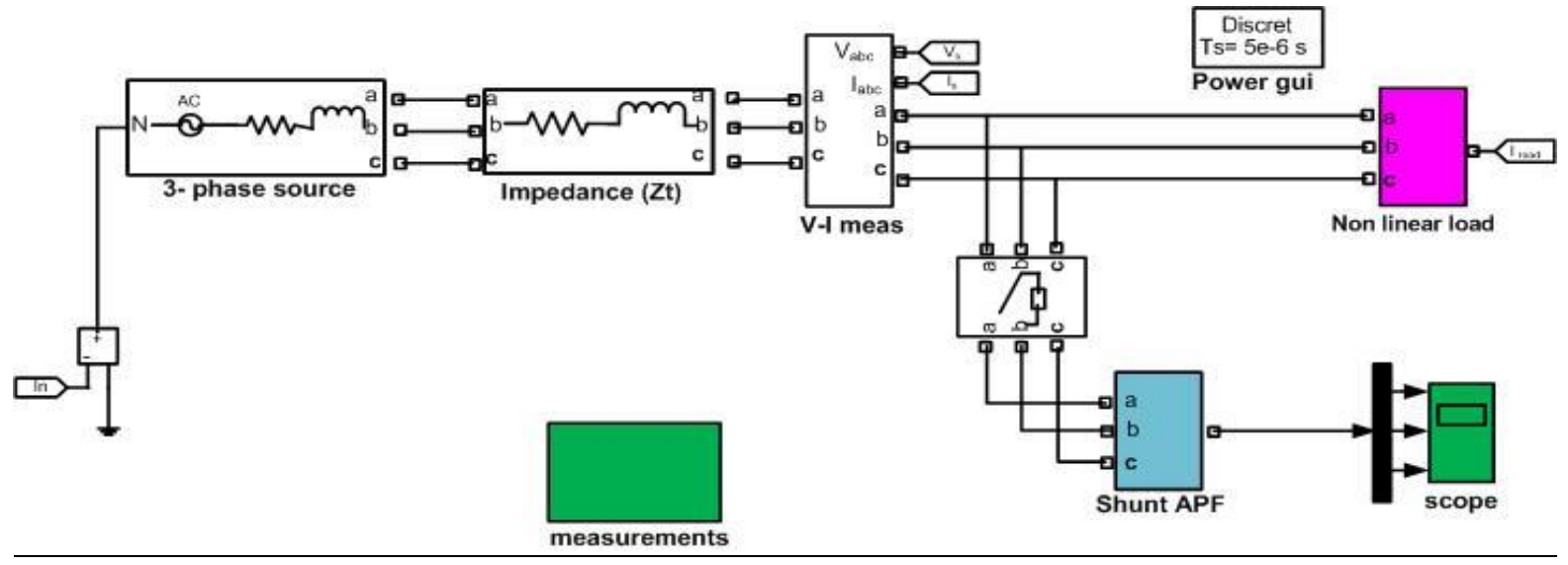

Fig .6. Three phase system with shunt active power filter.

Table 1. The proposed system parameters.

\begin{tabular}{|c|c|}
\hline $\begin{array}{c}\text { Three phase source voltage, } \\
\mathrm{V}_{\mathrm{s}}\end{array}$ & $\mathrm{V}=400 \mathrm{~V}$ \\
\hline Frequency, $\mathrm{f}$ & $50 \mathrm{~Hz}$ \\
\hline Source resistance, $\mathrm{R}_{\mathrm{s}}$ & $0.01 \Omega$ \\
\hline Source inductance, $\mathrm{L}_{\mathrm{s}}$ & $1 \mu \mathrm{H}$ \\
\hline Load first phase $(\mathrm{A})$ & $\mathrm{R}_{\mathrm{a}}=4 \Omega$ \\
Load second phase $(\mathrm{B})$ & $\mathrm{R}_{\mathrm{b}}=4 \Omega$ \\
Load third phase $(\mathrm{C})$ & $\mathrm{R}_{\mathrm{c}}=3 \Omega$ \\
\hline Filter inductance, $\mathrm{L}_{\mathrm{f}}$ & $2 \mathrm{mH}$ \\
\hline Filter DC capacitance, $\mathrm{C}_{\mathrm{dc}}$ & $200 \mu \mathrm{F}$ \\
\hline DC reference voltage, $\mathrm{V}_{\mathrm{dc}}$ & $1200 \mathrm{~V}$ \\
\hline
\end{tabular}

First Case: Figure 7 shows the simulation results of the compared APF compensation strategies when the ideal source voltages supply and nonlinear load. The waveforms shown from the top to the bottom are source voltages, load currents, source currents of compensation by using PQ method, Adaptive PLL method, DQ method, and SD method. As shown in Fig. 7, all of the proposed compensation strategies work very well to compensate harmonics. Table 2 shows the values of total harmonic distortion of source current, it is clear that the THD of the four methods has low values. The source neutral current under balanced source voltage and nonlinear load is shown in Fig. 8. It is shown that the neutral current of the source is very high as a results of nonlinearity and unbalanced characteristics of the load before, A shunt active power filter is applied. After, A shunt active power filter is applied, the neutral current of the source is negligible for four method.

\begin{tabular}{|c|c|c|c|c|c|}
\hline \multicolumn{7}{|c|}{ Table 2: Source current THD for case (1). } \\
\hline Current & Before filter & PQ & Adaptive PLL & DQ & SD \\
\hline $\mathrm{I}_{\mathrm{a}}$ & $129.17 \%$ & $3.26 \%$ & $2.15 \%$ & $2.85 \%$ & $4.14 \%$ \\
\hline $\mathrm{I}_{\mathrm{b}}$ & $130.73 \%$ & $3.55 \%$ & $2.23 \%$ & $3.27 \%$ & $4.82 \%$ \\
\hline $\mathrm{I}_{\mathrm{c}}$ & $98.44 \%$ & $7 \%$ & $1.88 \%$ & $3.34 \%$ & $5.41 \%$ \\
\hline
\end{tabular}



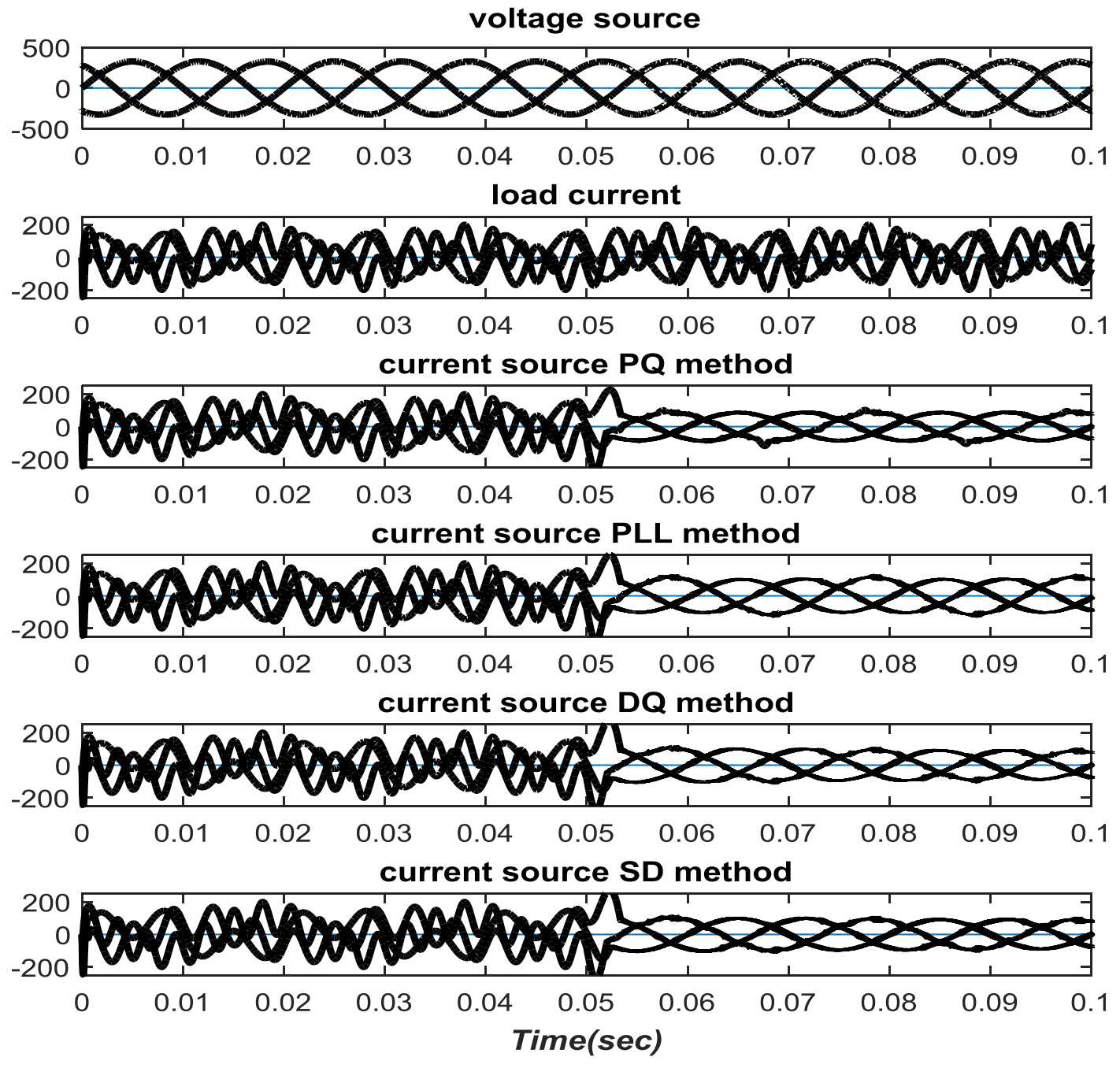

Fig .7. Voltage Source, load current and compensated source current waveforms for Case (1).

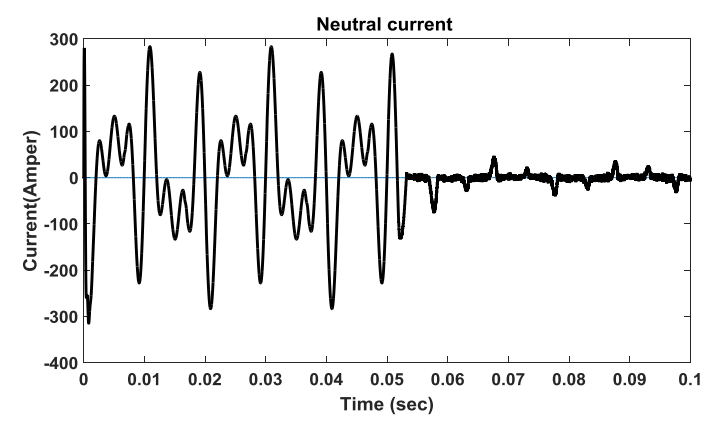

Fig. 8. Neutral current waveform 
Second case: Figure9 shows the simulation results of the compared APF compensation strategies when the three phase source voltages are assumed distortion and nonlinear load. In Fig.9, the order of the figure as in the previous case. As shown in Fig. 9, PQ method and SD method have a bad performance. The total harmonics distortion of the source current in table 3 show the superiority of the Adaptive PLL and DQ methods compared to PQ and SD methods.
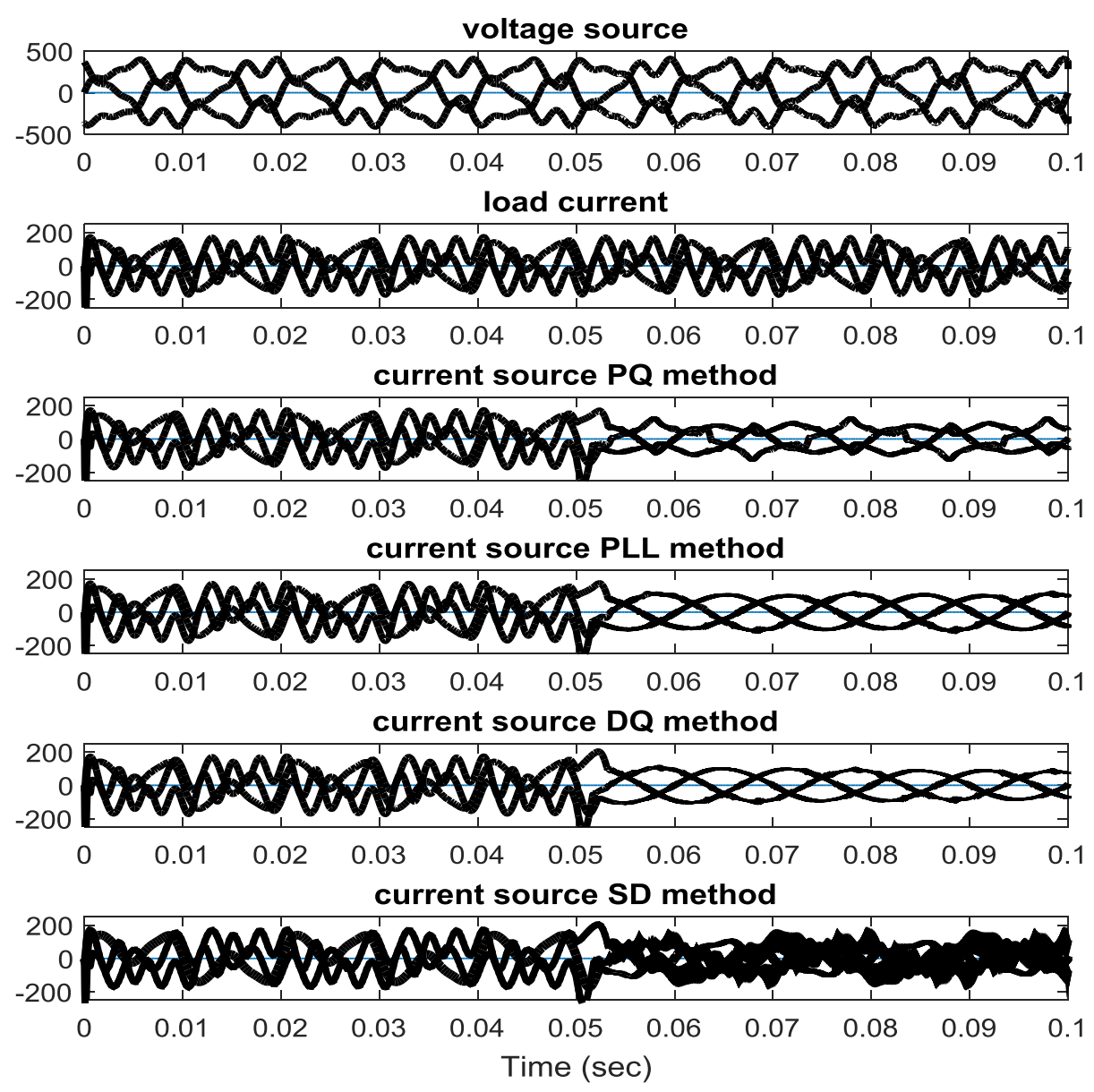

Fig .9. Voltage Source, load current and compensated source current waveforms for Case (2).

Table 3: Source current THD for case(2).

\begin{tabular}{|c|c|c|c|c|c|c|}
\hline$\varnothing$ & Current & Voltage & PQ & $\begin{array}{c}\text { Adaptive } \\
\text { PLL }\end{array}$ & DQ & SD \\
\hline A & $131.43 \%$ & $25.05 \%$ & $26.93 \%$ & $4.06 \%$ & $3.11 \%$ & $24.97 \%$ \\
\hline B & $119.8 \%$ & $25.04 \%$ & $25.29 \%$ & $4.31 \%$ & $3.77 \%$ & $23.53 \%$ \\
\hline C & $87.36 \%$ & $25.09 \%$ & $31.78 \%$ & $4.18 \%$ & $3.99 \%$ & $24.57 \%$ \\
\hline
\end{tabular}

Third Case: in this case, the three phase source voltages are assumed unbalanced at magnitude and nonlinear load. The three phase source voltage values are $\mathrm{V}_{\mathrm{a}}=320 \mathrm{~V}$, $\mathrm{V}_{\mathrm{b}}=400 \mathrm{~V}$ and $\mathrm{V}_{\mathrm{c}}=440 \mathrm{~V}$. In Fig.10, the waveforms of the four methods are given. As shown in Fig. 10, Adaptive PLL method, DQ method, and SD method work very well to compensate harmonics but PQ method has a bad performance. The total harmonics distortion are shown in Table 4 for each method. 

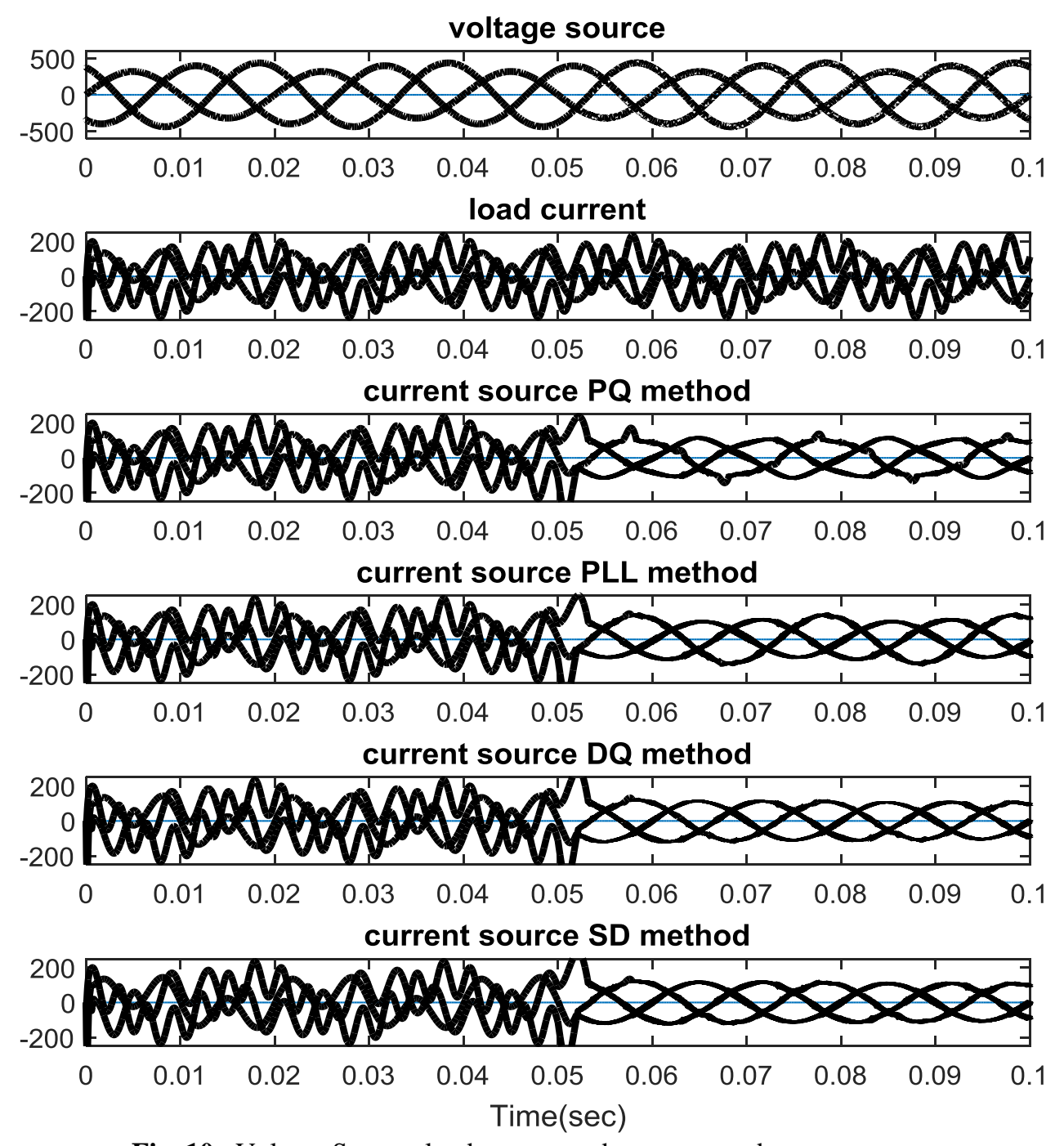

Fig .10. Voltage Source, load current and compensated source current waveforms for Case (3).

Table 4. Source current THD for case (3).

\begin{tabular}{|c|c|c|c|c|c|}
\hline Current & Before filter & PQ & $\begin{array}{c}\text { Adaptive } \\
\text { PLL }\end{array}$ & DQ & SD \\
\hline Ia & $131.84 \%$ & $8.8 \%$ & $4.02 \%$ & $2.56 \%$ & $3.75 \%$ \\
\hline Ib & $106.66 \%$ & $8.16 \%$ & $3.74 \%$ & $2.57 \%$ & $4.17 \%$ \\
\hline Ic & $72.95 \%$ & $13.56 \%$ & $3.21 \%$ & $2.75 \%$ & $4.58 \%$ \\
\hline
\end{tabular}




\section{CONCLUSION}

A comparison of four control techniques applied for the generation of the reference current for shunt active power filters was presented. The four controllers performance are tested under operating conditions. The compensation performance of the different techniques is almost similar under ideal balanced conditions. D-Q method and Adaptive PLL method have good results under different operating conditions, i.e. harmonically load current, unbalanced and distorted supply voltage. P-Q and SD methods has acceptable performance with nonlinear loads. SD gives acceptable results with unbalanced supply voltage and harmonically loads. P-Q performance is unsatisfied with unbalanced and / or distorted voltage source. But PQ method is consider the simplest method because axes transformation from stationary frame to synchronous frame is not required.

\section{REFERENCE}

[1] R. Belaidi, A. Haddouche, and $\mathrm{H}$. Guendouz. "Fuzzy logic controller based three-phase shunt active power filter for compensating harmonics and reactive power under unbalanced mains voltages." Energy Procedia 18, 560-570, 2012.

[2] Martins António, José Ferreira, and HelderAzevedo. "Active Power Filters for Harmonic Elimination and Power Quality Improvement." Power Quality. InTech, 2011.

[3] Ali Emadi, NasiriAbdolhosein, and B. BekiarovStoyan. "Uninterruptible power supplies and active filters" CRC press, 2004.

[4] K. Lee, "Power quality analysis and new harmonic and unbalance control of modern adjustable speed drives or uninterruptible power systems under nonideal operating conditions" University of Wisconsin-Madison, 2008.

[5] H. Wang "Harmonic impact of modern residential loads on distribution power system and mitigation solutions" Master thesis, University of Alberta, 2011.

[6] Adam, George, Alina G. Stan, and Gheorghe Livint. "A Matlab-Simulink Approach to Shunt Active Power Filters." Proceedings 25th European Conference on Modelling and Simulation (ECMS), 2011.

[7] Z. Yuan "Harmonics regulation and mitigation in low-voltage distribution systems of large buildings" Doctoral dissertation, The Hong Kong Polytechnic University, 2008.

[8] Y. P. Obulesu, M. Venkateswara Reddy, and Y. Kusumalatha "A\% THD analysis of industrial power distribution systems with active power filter-case studies." International Journal of Electrical Power \& Energy Systems 60, 107-120, 2014.

[9] Mittal, Kavya, and AnkitaKosti. "Hybrid active power filter for power quality improvement." International Journal of Emerging Technology and Advanced Engineering, 2014.

[10] Yang, Nien-Che, and Minh-Duy Le. "Optimal design of passive power filters based on multi-objective bat algorithm and pareto front." Applied Soft Computing, 35, 257-266, 2015.

[11] D. Khera "Simulation of voltage source converter based shunt active filter in EMTP-RV" Doctoral dissertation, UOIT, 2010.

[12] E. K. Almaita, "Adaptive radial basis function neural networks-based real time harmonics estimation and PWM control for active power filters" Western Michigan University, 2012.

[13] M. F. M. Hasan "A shunt active filter for distorted voltage conditions" Doctoral dissertation at The Petroleum Institute, United Arab Emirates, 2013.

[14] R. Zahira, and A. Peer Fathima. "A technical survey on control strategies of active filter for harmonic suppression." Procedia Engineering 30, 686-693, 2012. 
[15] Afonso, João L., Carlos Couto, and Júlio S. Martins. "Active filters with control based on the pq theory." IEEE Industrial Electronics Society Newsletter Vol. 47, No.3, pp. 5-10, Sept. 2000.

[16] P. Xiao, "New techniques to improve power quality and evaluate stability in modern all-electric naval ship power systems. Missouri University of Science and Technology, 2007.

[17] Patil, Sagar S., and R. A. Metri. "Power quality improvement using shunt active power filter." IEEE International Conference on Data Management, Analytics and Innovation (ICDMAI), 2017.

[18] R. Musa. "Improving the safety operation of three-phase shunt active filter" Doctoral dissertation, 2017.

[19] Msigwa, Consalva J., Beda J. Kundy, and Bakari MM Mwinyiwiwa. "Control algorithm for shunt active power filter using synchronous reference frame theory" World Academy of Science, Engineering and Technology, 58, 2009.

[20] Guo, Xiao-Qiang, Wei-Yang $\mathrm{Wu}$, and HeRongGu. "Phase locked loop and synchronization methods for gridinterfaced converters: a review" PrzegladElektrotechniczny, 87, 4, 182-187, 2011.

[21] P. JenoPaul, "Adapitive PLL controller based shunt active filter for power quality improvement in Matrix converter." International Journal Of Applied Engineering Research, Dindigul, Volume 1, No 4, 2011

[22] D- Jovcic "Phase locked loop system for FACTS" IEEE Transactions on Power Systems, 18(3), 1116-1124, 2003.

[23] S. Premalatha, S. S. Dash and P. C. Babu, "Power quality improvement features for a distributed generation system using shunt active power filter" ProcediaEng, 64, 265-274, 2013.

[24] Satpathy, S., \&Bebarta, S. S, "Power Quality Improvement in 3-Phase System
Using Shunt Active Filter"National Institute of Technology Rourkela,2013.

[25] C. Rejil, M.Anzari, and K. R. Arun, "Design and simulation of three phase shunt active power filter using SRF theory" Advance in Electronic and Electric Engineering, 3(6), pp. 651-660, 2013.

[26] N. Gupta, S. P. Singh, and S. P. Dubey, "Fuzzy logic controlled shunt active power filter for reactive power compensation and harmonic elimination" $2^{\text {nd }}$ International Conference on Computer and Communication Technology (ICCCT), pp. 82-87, September 2011.

[27] M. R. Gopal, S. Yarnagula "Simulation and Analysis of Shunt Active Power Filter for Power Quality Improvement" International Journal of Advanced Trends in Computer Science and Engineering, 3(1), pp. 26-31, 2014.

[28] C. L. Chen, C. E. Lin, and C. L. Huang "Reactive and harmonic current compensation for unbalanced three-phase systems using the synchronous detection method" Electric power systems research, 26(3), 163-170, 1993.

[29] C. L. Chen, C. E. Lin "An active filter for an unbalanced three-phase system using the synchronous detection method" Electric power systems research, 36(3), pp. 157-161, 1996.

[30] E. L. Mercy, R. Karthick, and S. Arumugam "A comparative performance analysis of four control algorithms for a three phase shunt active power filter" International Journal of Computer Science and Network Security, 10(6), pp. 1-7, 2011. 